\title{
miR-15a induces cell apoptosis by targeting BCL2L2 and BCL2 in HPV-positive hypopharyngeal squamous cell carcinoma
}

\author{
WUHAO LU ${ }^{1 *}$, LONG FENG $^{2 *}$, YAN ZHANG ${ }^{2}$, YUNYUN MA ${ }^{3},{\text { PING } \mathrm{LI}^{4}, \text { YUANYUAN WANG }}^{5}$, \\ YUWEN DU ${ }^{5}$, XIAONAN CHEN ${ }^{5}$, SHUJUN WU ${ }^{4}$, GUOQIANG ZHAO 5 and WEIHUA LOU ${ }^{1}$ \\ ${ }^{1}$ Department of Otolaryngology-Head and Neck Surgery, The First Affiliated Hospital of Zhengzhou University, Zhengzhou, \\ Henan 450052; ${ }^{2}$ Department of Pathogenic Organism Biology, Henan University of Chinese Medicine, Zhengzhou, \\ Henan 450008; ${ }^{3}$ Department of Immunology and Microbiology, Henan Medical College, Zhengzhou, Henan 451191; \\ ${ }^{4}$ Department of Respiratory Medicine, The First Affiliated Hospital of Zhengzhou University, Zhengzhou, Henan 450052; \\ ${ }^{5}$ College of Basic Medical Sciences, Zhengzhou University, Zhengzhou, Henan 450001, P.R. China
}

Received April 27, 2016; Accepted June 8, 2016

DOI: $10.3892 /$ or.2016.5049

\begin{abstract}
Aberrant expression of miR-15a was recently reported in several types of cancers; however, its role in HPV-positive hypopharyngeal squamous cell carcinoma (HSCC) remains obscure. In the present study, we investigated the mechanism by which miR-15a induces HPV-positive HSCC apoptosis. Synthetic miR-15a mimics were transfected into FaDu cells (HPV-negative), and the miR-15a inhibitor was transfected into HPV-positive HSCC cells. miR-15a expression was analyzed by RT-PCR, and BCL2L2 and BCL2 were analyzed by western blotting. The Hochest 33342/propidium iodide (PI) and caspase-3/-9 assays, and Annexin V staining were used to assess the effect of miR-15a on apoptosis. After transfection, overexpression of miR-15a in the FaDu cells was associated with significantly decreased BCL2L2 and BCL2 expression and a significant increase in the apoptosis rate. The opposite results were observed in HPV-positive HSCC, where downregulation of miR-15a suppressed apoptosis. These findings indicate that miR-15a acts as a tumor suppressor in HPV-positive HSCC.
\end{abstract}

Correspondence to: Professor Wuhao Lu, Department of Otolaryngology-Head and Neck Surgery, The First Affiliated Hospital of Zhengzhou University, 1 Jianshe Road, Zhengzhou, Henan 450052, P.R. China

E-mail: luwuhao@126.com

Professor Guoqiang Zhao, College of Basic Medical Sciences, Zhengzhou University, 100 Kexue Road, Zhengzhou, Henan 450001, P.R. China

E-mail: zhaogq@126.com

${ }^{*}$ Contributed equally

Key words: miR-15a, BCL2L2, BCL2 HPV, hypopharyngeal squamous cell carcinoma, HSCC, apoptosis

\section{Introduction}

Hypopharyngeal squamous cell carcinoma (HSCC) is a common type of malignant tumor among head and neck squamous cell carcinomas (HNSCCs) (1-3). In China, the morbidities of lip, oropharynx, hypopharynx and larynx carcinomas were reported as $0.04-0.14,1-2,0.15-0.8$ and $3-5 / 100,000$, respectively (4-6). Tobacco and alcohol are the predominant risk factors in patients with HNSCC. However, human papillomavirus (HPV) type 16 DNA is found in up to $30 \%$ of these cancers, and such cases of HNSCC are often found in individuals without the risk factors of alcohol and tobacco use (7-10). HPV-positive cases of HNSCC have a much better disease outcome compared to HNSCC cases lacking HPV (11-13). Differences in microRNA (miRNA) expression may affect their clinical outcomes (14).

miRNAs are small, non-coding RNAs $~ 18-24$ nucleotides in length that negatively regulate gene expression at the post-transcriptional and/or translational level by binding to complimentary sequences in the 3'-untranslated regions (3'-UTRs) of target mRNAs (15). miRNAs regulate up to $30 \%$ of human protein coding genes (16) and can function as oncogenes or tumor-suppressor genes by modulating the expression of their targets in many types of cancers (17).

Recent studies indicate that miR-15a is downregulated in chronic lymphocytic leukemia (18), prostate cancer (19), osteosarcoma (20), keratocystic odontogenic tumors (21) and breast cancer (22). Overexpression of miR-15a was found to downregulate BCL-2 and induce the apoptosis of MCF-7 breast cancer cells (23). However, the mechanism by which miR-15a contributes to HPV-positive HSCC tumorigenesis remains unclear.

Our previous study (24) showed that miR-15a is highly expressed in HPV-positive tissues and cells. It may be speculated that HPV-positive tumors have a better prognosis. In the present study, a synthetic miR-15a inhibitor and miR-15a mimics were transfected into HPV-positive and HPV-negative cell lines, respectively, to examine the effects of miR-15a on these cells.

The aim of the present study was to investigate the mechanism by which miR-15a induces HPV-positive HSCC 
Table I. miR-15a, U6, BCL2, BCL2L2 and GAPDH reverse transcription (RT) primers.

\begin{tabular}{|c|c|c|c|}
\hline Name & RT primers & & PCR primers \\
\hline $\operatorname{miR}-15 a$ & $\begin{array}{l}\text { 5'-GTCGTATCCAGTGCAGGGTCCGAGG } \\
\text { TATTCGCACTGGATACGACATCGTCG-3' }\end{array}$ & $\begin{array}{l}\mathrm{F} \\
\mathrm{R}\end{array}$ & $\begin{array}{l}\text { 5'-TCCGAGTGTTTGGTAATACA-3' } \\
\text { 5'-GTGCAGGGTCCGAGGT-3' }\end{array}$ \\
\hline U6 nRNA & $\begin{array}{l}\text { 5'-GTCGTATCCAGTGCAGGGTCCGAGG } \\
\text { TATTCGCACTGGATACGACAAAATA-3' }\end{array}$ & $\begin{array}{l}\mathrm{F} \\
\mathrm{R}\end{array}$ & $\begin{array}{l}\text { 5'-TCCGATCGTGAAGCGTTC-3' } \\
\text { 5'-GTGCAGGGTCCGAGGT-3' }\end{array}$ \\
\hline BCL-2 & $\operatorname{Oligo}(\mathrm{dT})_{18}$ primer & $\begin{array}{l}\mathrm{F} \\
\mathrm{R}\end{array}$ & $\begin{array}{l}\text { 5'-ACGACTTCTCCCGCCGCTA-3' } \\
\text { 5'-CATCTCCCGGTTGACGCTCT-3' }\end{array}$ \\
\hline BCL2L2 & Oligo $(\mathrm{dT})_{18}$ primer & $\begin{array}{l}\mathrm{F} \\
\mathrm{R}\end{array}$ & $\begin{array}{l}\text { 5'-TGAGTTCGAGACCCGCTTC-3' } \\
\text { 5'-AAAAGTTCATCGGAGACCTG-3' }\end{array}$ \\
\hline GAPDH & Oligo $(\mathrm{dT})_{18}$ primer & $\begin{array}{l}\mathrm{F} \\
\mathrm{R}\end{array}$ & $\begin{array}{l}\text { 5'-CCACCCATGGCAAATTCCATGGCA-3' } \\
\text { 5'-TCTAGACGGCAGGTCAGGTCCCC-3' }\end{array}$ \\
\hline
\end{tabular}

F, forward; R, reverse.

apoptosis. The novel tumor-suppressive miR-15a-mediated cancer pathways identified herein provide new insights into the potential mechanisms of HPV-positive HSCC and apoptosis and suggest potential therapeutic targets for the treatment of HPV-positive HSCC.

\section{Materials and methods}

Patients and tumor samples. Tumor samples were collected from patients with pharyngeal cancer who had undergone surgery at the Department of Otolaryngology-Head and Neck Surgery, The First Affiliated Hospital of Zhengzhou University (Zhengzhou, China). Patients recruited to the present study had not undergone chemotherapy, radiotherapy or immunotherapy. Collected tumor samples were frozen in liquid nitrogen and stored at $-80^{\circ} \mathrm{C}$ until required. The present study was approved by the Ethics Committee of Zhengzhou University and informed consent was obtained from each patient.

Cell lines and culture conditions. FaDu cells were purchased from the Type Culture Collection of the Chinese Academy of Sciences (Shanghai, China). HPV-positive HSCC were established using lentiviral vectors expressing the E6 and E7 proteins of HPV-16. Positive clones were identified according to the expression of enhanced green fluorescent protein (EGFP). Cells were cultured in Dulbecco's modified Eagle's medium (DMEM) supplemented with 10\% fetal bovine serum (FBS) (both from Gibco-BRL, Co., Ltd., Carlsbad, CA, USA) and grown in a $37^{\circ} \mathrm{C} / 5 \% \mathrm{CO}_{2}$ incubator.

miR-15a transfection. miR-15a mimics, miR-15a inhibitors and their negative controls were obtained from GenePharma Co., Ltd. (Shanghai, China). For transfections, cells $\left(2 \times 10^{6}\right)$ were added into each well of a 6 -well plate and cultured with DMEM without serum and antibiotics. When the density of cells reached $50-60 \%$, mimics and inhibitor were transfected into FaDu cells (HPV-negative) and HPV-positive HSCC cells using the Lipofectamine transfection reagent (Invitrogen, Carlsbad, CA, USA). The mimics/inhibitor and Lipofectamine transfection reagent were each diluted in $500 \mu$ l DMEM at a ratio of $1 \mu \mathrm{g}: 3 \mu \mathrm{l}$ and incubated for $5 \mathrm{~min}$ at room temperature (RT). The two mixtures were then gently combined and incubated for a further $30 \mathrm{~min}$ at RT. Subsequently, 1,000 $\mu \mathrm{l}$ of the complexes were added to each well. After 4-6 h of incubation, the medium was replaced by DMEM with $10 \%$ FBS. Cells were incubated at $37^{\circ} \mathrm{C}$ in a $\mathrm{CO}_{2}$ incubator for $48 \mathrm{~h}$ before further testing.

Quantitative reverse-transcription polymerase chain reaction ( $q R T-P C R)$. Total RNA was extracted from cells using the TRIzol reagent (Invitrogen) according to the manufacturer's protocol. RNA concentration was spectrophotometrically determined. RNA quality was confirmed using a NanoDrop 1000 Spectrophotometer (Thermo Fisher Scientific, Wilmington, DE, USA). Conversion to cDNA was performed using ReverTra Ace ${ }^{\circledR}$ qPCR RT kit (Toyobo, Osaka, Japan). qRT-PCR was carried out using the Maxima SYBR-Green qPCR kit (Thermo Fisher Scientific) on a 7500 Fast Real-Time PCR system (Applied Biosystems, Foster City, CA, USA). U6 was used as an internal normalized reference for miRNA expression, and GAPDH was used as an endogenous control for mRNA expression. PCR was performed with primers specific for miR-15a, U6, BCL2, BCL2L2 and GAPDH. The primer sequences are shown in Table I. The PCR parameters for relative quantification were as follows: $5 \mathrm{~min}$ at $94^{\circ} \mathrm{C}$, followed by 30 cycles of $30 \mathrm{sec}$ at $94^{\circ} \mathrm{C}, 45 \mathrm{sec}$ at $55^{\circ} \mathrm{C}$ and $45 \mathrm{sec}$ at $72^{\circ} \mathrm{C}$. Each sample was tested in triplicate. The fold-change of target miRNA/mRNA expression was calculated based on the threshold cycle (Ct) with the $2^{-\Delta \Delta \mathrm{Ct}}$ method (25).

Western blot analysis. FaDu cells and HPV-positive HSCC were lysed and total proteins were isolated. Total cell protein concentrations were determined using the bicinchoninic acid protein assay kit (Pierce Biotechnology, Inc., Rockford, IL, USA). Equal amounts of protein $(10 \mu \mathrm{g})$ from the cell lysates were separated by $12 \%$ sodium dodecyl sulfate-polyacrylamide gel electrophoresis (Bio-Rad Laboratories, Inc., Hercules, CA, USA). Electrophoresed proteins were transferred to nitrocellulose membranes (GE Healthcare, Logan, UT, USA), which were subsequently blocked with $5 \%(\mathrm{w} / \mathrm{v})$ non-fat 


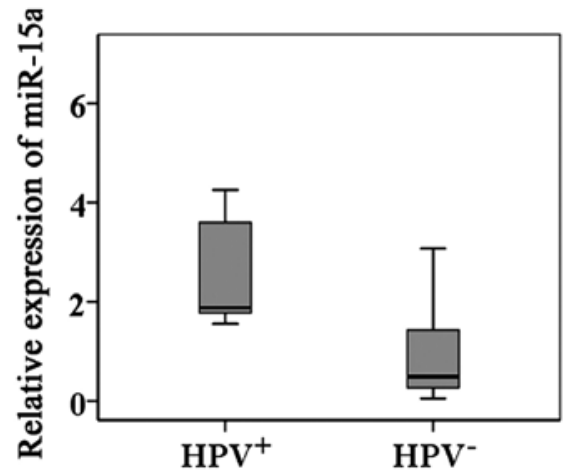

Figure 1. miR-15a is overexpressed in the HPV-positive pharyngeal squamous carcinoma tissues. miR-15a expression was assessed by qRT-PCR in samples from patients. Graph represents the $2^{-\Delta \Delta C t}$ values $\pm S E M ;{ }^{*} p<0.05$.

milk and incubated overnight at $4{ }^{\circ} \mathrm{C}$ with antibodies against BCL2 (diluted 1:1,000; Cell Signaling Technology, Danvers, MA, USA) and BCL2L2 (1:1,000; Santa Cruz Biotechnology, Santa Cruz, CA, USA). The membranes were then incubated with the appropriate horseradish peroxidase-conjugated secondary antibody (1:2,000; Santa Cruz Biotechnology). Protein band density was quantified using a Molecular Dynamics densitometer (Molecular Dynamics, Sunnyvale, CA, USA). Glyceraldehyde 3-phosphate dehydrogenase was used as an internal reference.

Analysis of apoptosis by Annexin V-APC/7-aminoactinomycin $D(7-A A D)$ staining. The Annexin V-APC apoptosis detection kit (Abcam, Cambridge, MA, USA) was used to detect and quantify apoptosis by flow cytometry. miR-15a mimics, miR-15a inhibitor, and their negative control groups of adherent cells were harvested and incubated with Annexin $\mathrm{V}$ incubation reagent (prepared by combining $10 \mu \mathrm{l}$ of 10X binding buffer, $10 \mu \mathrm{l}$ of 7-AAD, $1 \mu \mathrm{l}$ Annexin V-APC and $79 \mu \mathrm{l}$ of deionized, distilled $\mathrm{H}_{2} \mathrm{O}$ ) at $10^{5}-10^{6}$ cells $/ 100 \mu \mathrm{l}$ for 15 min at RT in the dark. All samples were processed by flow cytometry (FACSCanto $^{\mathrm{TM}}$ II; BD Biosciences). FACS analyses were performed at least three times with reproducible results.

Hoechst 33342 and propidium iodide (PI) staining. Hoechst 33342 and PI staining was used to evaluate the morphological changes in apoptotic cells. The cells were stained with $10 \mu \mathrm{g} / \mathrm{ml}$ Hoechst 33342 and $10 \mu \mathrm{g} / \mathrm{ml}$ PI for $30 \mathrm{~min}$ at $37^{\circ} \mathrm{C}$. Following two successive washes with phosphate-buffered saline (PBS), images of the cells were captured with a digital camera attached to a fluorescence microscope (IX70; Olympus Corporation, Tokyo, Japan).

Caspase-3/-9 activity assay. The activity of caspase-3/-9 was determined using the Colorimetric Assay kit (KeyGen Biotech Co., Ltd., Nanjing, Jiangsu, China). Cell lysates were prepared and incubated with reaction buffer containing caspase-3/-9 substrate after treatments as indicated. Assays were performed on 96 -well plates by incubating $10 \mathrm{ml}$ of cell lysate/sample in $80 \mathrm{ml}$ of reaction buffer containing $10 \mathrm{ml}$ caspase-3/-9 substrate at $37^{\circ} \mathrm{C}$ for $2 \mathrm{~h}$ according to the manufacturer's protocol. Cell fluorescence intensity at $465 \mathrm{~nm}$ was measured by ELISA tablet counter for quantitative assessment.

Statistical analysis. All statistical analyses were performed using SPSS 17.0 (SPSS, Inc., Chicago, IL, USA) software. Multiple comparisons between parental and control groups were made using Tukey's honest significant difference test. The expression levels of miRNAs in cells were analyzed using the Wilcoxon signed-rank test. Values are presented as the mean \pm SD. A p-value $<0.05$ was considered to indicate a statistically significant result.

\section{Results}

miR-15a is overexpressed in HPV-positive HSCC samples. miR-15a expression was significantly higher in samples from HPV-positive than in those from HPV-negative HSCC patients (Fig. 1).

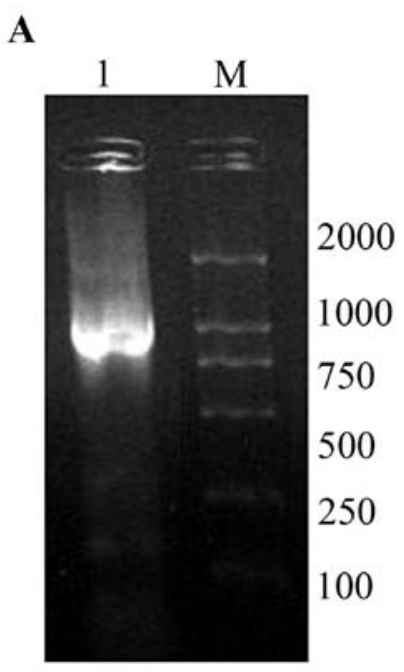

B

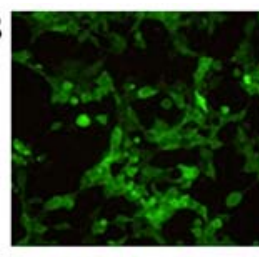

HPV-16 E6-E7

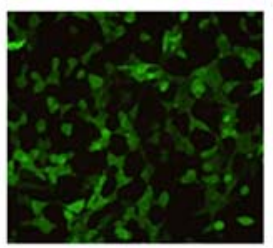

Empty vector control

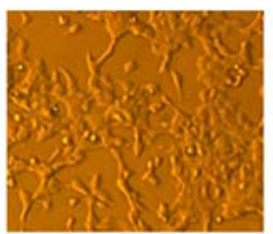

Blank control

Figure 2. E6-E7 is overexpressed in the stably transfected FaDu cells. (A) The HPV-16 E6-E7 gene was detected by PCR. (B) Positive clones were identified by positive EGFP expression. 
Table II. Relative amounts of miR-15a from three independent experiments.

\begin{tabular}{lcccc}
\hline Group & Ct miR-15a & $\mathrm{Ct} \mathrm{U6}$ & $\Delta \mathrm{Ct}$ & $2^{-\Delta \mathrm{Ct}}$ \\
\hline HPV-E6-E7 (HPV-positive) & $22.53 \pm 0.62$ & $24.58 \pm 0.63$ & $-2.05 \pm 0.47$ & $4.15 \pm 0.13^{\mathrm{a}}$ \\
Empty vector control & $28.37 \pm 0.32$ & $26.09 \pm 0.40$ & $2.08 \pm 0.08$ & $0.20 \pm 0.03$ \\
FaDu cells (HPV-negative) & $26.82 \pm 0.45$ & $24.61 \pm 0.47$ & $2.21 \pm 0.03$ & $0.21 \pm 0.02$
\end{tabular}

miR-15a mRNA was significantly increased in the HPV-positive FaDu cells compared with that noted in the empty vector control and FaDu cells (HPV-negative), blank control and scramble groups; ${ }^{\mathrm{a}} \mathrm{p}<0.05$.

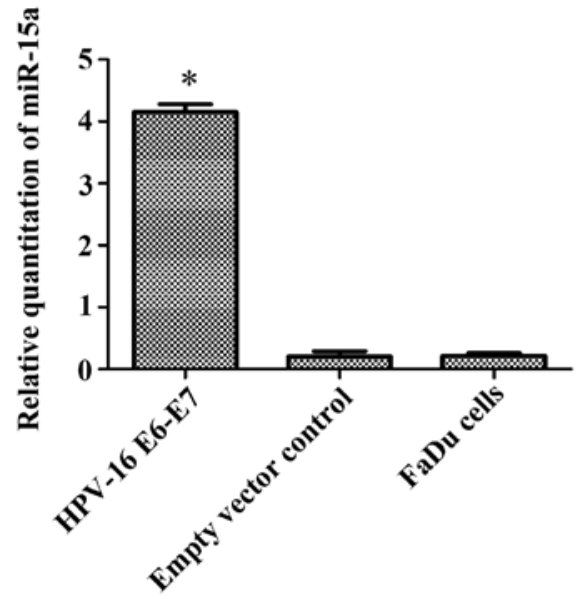

Figure 3. miR-15a is overexpressed in HPV-positive HSCC. miR-15a mRNA was quantified by real-time PCR. Data represent the mean \pm SD of four independent experiments. miR-15a mRNA was increased in HPV-16 E6-E7-positive FaDu cells compared with the control and FaDu cells ("p<0.05).

Overexpression of HPV-16 E6-E7 in HPV-positive hypopharyngeal squamous cells. HPV-16 E6-E7-positive FaDu cells were established by recombinant lentivirus infection and termed HPV-positive hypopharyngeal squamous cell carcinoma. PCR was used to identify the E6 and E7 genes. Analysis by $1.5 \%$ agarose gel electrophoresis showed a bright band at $\sim 750$ bp consistent with the theoretical value of the HPV-16 E6-E7 gene sequence. Positive clones were identified based on the expression of EGFP (Fig. 2).

Overexpression of miR-15a in HPV-positive HSCC. Before transfection, the expression of miR-15a was detected in $\mathrm{FaDu}$ cells (HPV-negative) and HPV-16 E6-E7-infected FaDu cells (HPV-positive) by real-time PCR. The results confirmed that miR-15a was overexpressed in the HPV-positive $\mathrm{FaDu}$ cells compared with the levels in normal FaDu cells (Table II and Fig. 3).

miR-15a is upregulated in FaDu cells and is downregulated in HPV-positive HSCC after transfection. To upregulate or downregulate miR-15a, cells were transfected with miR-15a mimics or inhibitor, which consisted of chemically modified sense or antisense oligonucleotides designed to specifically target mature miR-15a. The efficient overexpression and downregulation of miR-15a in cells is shown in Fig. 4. Cellular
A
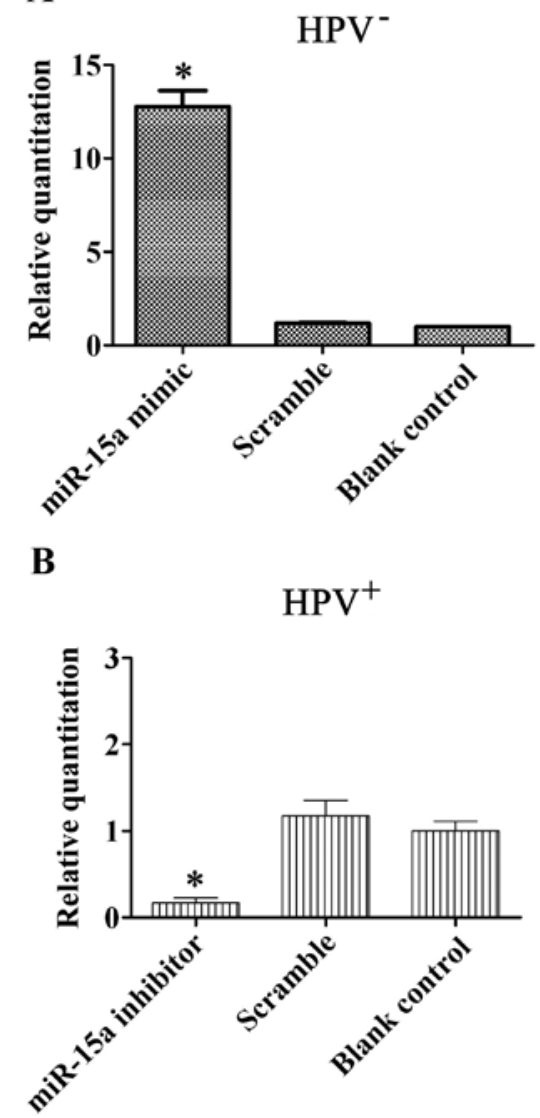

Figure 4. (A) miR-15a mRNA upregulation in miR-15a mimic-transfected FaDu cells $\left(\mathrm{HPV}^{-}\right)$and $(\mathrm{B})$ downregulation in miR-15a inhibitor-transfected HPV-positive HSCC $\left(\mathrm{HPV}^{+}\right)$. Cells were incubated with different synthetic oligonucleotides as described in Materials and methods, and miR-15a mRNA was quantified by real-time PCR. Data represent the mean \pm SD of four independent experiments. miR-15a mRNA was increased in the miR-15a mimic-treated cells compared with the control and scramble groups; ${ }^{*} \mathrm{p}<0.01$.

miR-15a levels were increased $\sim 15$-fold when FaDu cells were transfected with miR-15a mimics, while these levels decreased when HPV-positive HSCC were treated with miR-15a inhibitor.

miR-15a expression is negatively correlated with BCL2L2 and $B C L 2$ expression. To assess the correlation between miR-15a and BCL2L2 or BCL2, BCL2L2 or BCL2 expression was evaluated in cells transfected with miR-15a mimics or inhibitor. Overexpression of miR-15a significantly suppressed 
A

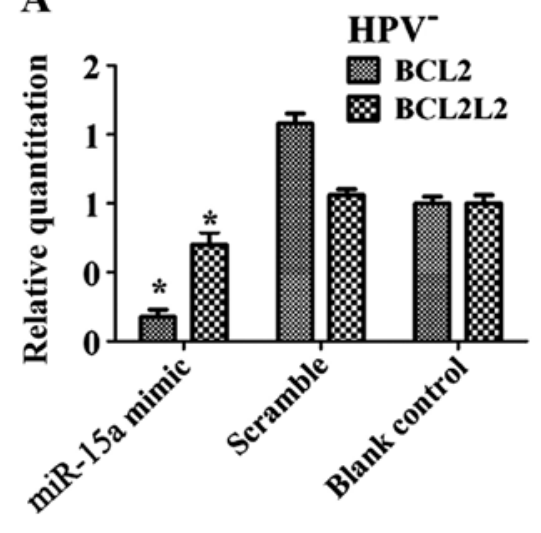

B

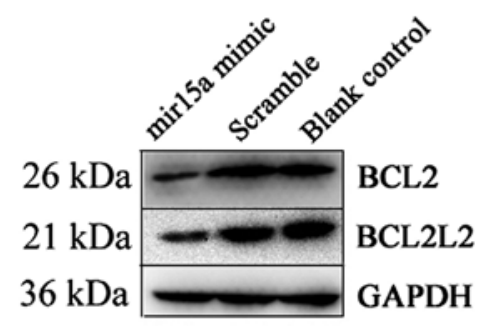

C

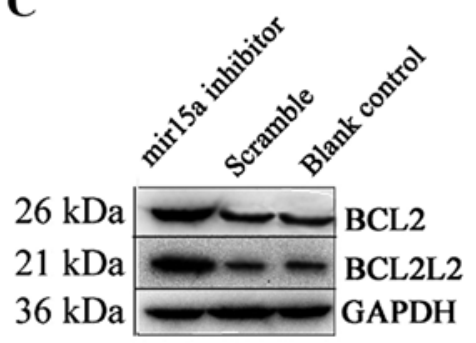

D

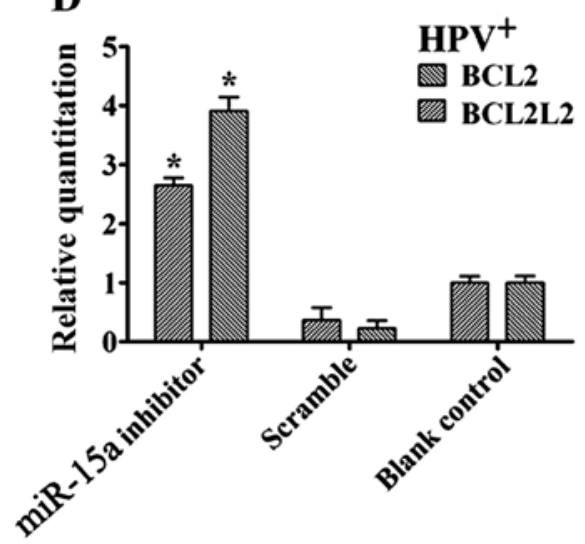

$\mathbf{E}$

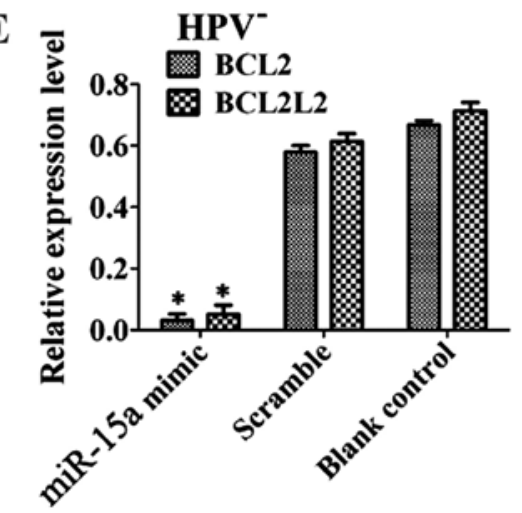

$\mathbf{F}$

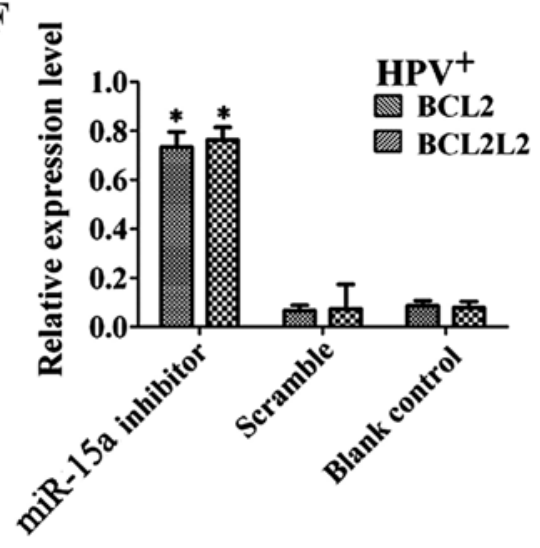

Figure 5. Overexpression of miR-15a significantly suppresses BCL2L2 and BCL2 mRNA and protein levels. Cells were incubated with different synthetic oligonucleotides as described in Materials and methods. (A and D) BCL2L2 and BCL2 mRNA was quantified by real-time PCR. Data represent the mean \pm SD of three independent experiments. BCL2L2 and BCL2 mRNA were decreased in the miR-15a mimic-treated cells and increased in the miR-15a inhibitortreated cells compared with the control and scramble groups. (B, C, E and F) Protein levels of BCL2L2 and BCL2 were measured by western blotting after transfection of miR-15a mimics, a miR-15a inhibitor and miR-control into HPV-positive and HPV-negative FaDu cells separately. GAPDH was used as an internal control $(\mathrm{p}<0.05)$.

BCL2L2 or BCL2 mRNA levels in the HPV-positive FaDu cells, whereas miR-15a knockdown had the opposite effect on BCL-2 and BCL2L2 expression in the HPV-positive cells (Fig. 5A and D). The downstream proteins of BCL2L2 and BCL2 were also analyzed. To determine the regulatory levels at which miR-15a modulates BCL2L2 and BCL2 protein expression, we repeated the above experiments and examined protein levels after transfections (Fig. 5B, C, E and F). The results of western blotting were consistent with those of realtime PCR and showed that overexpression or knockdown of miR-15a suppressed or increased BCL2L2 and BCL2 protein levels in the cells.
miR-15a overexpression induces apoptosis. We next analyzed the biological consequences of the miR-15a-driven repression of BCL2L2 and BCL2 expression in HPV-positive HSCC. Since BCL2L2 and BCL2 are involved in the regulation of cell apoptosis, we evaluated the effects of miR-15a on the apoptosis of HPV-positive HSCC using Annexin V-APC/7-AAD staining. Statistically significant $(\mathrm{p}<0.05)$ increases in Annexin V apoptotic cells were observed in the miR-15a mimic-treated FaDu cells $(14.30 \pm 1.24 \%)$ compared to the scramble control $(4.33 \pm 2.89 \%)$ and blank control $(2.80 \pm 0.71 \%)$ cells. The apoptosis rate in the miR-15a inhibitor-treated HPV-positive HSCC was decreased $(2.30 \pm 0.61 \% ; \mathrm{p}<0.05)$ compared 
A
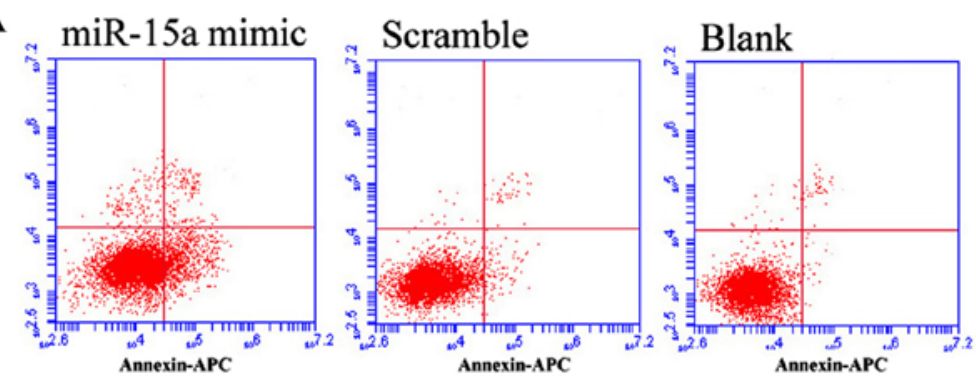

B
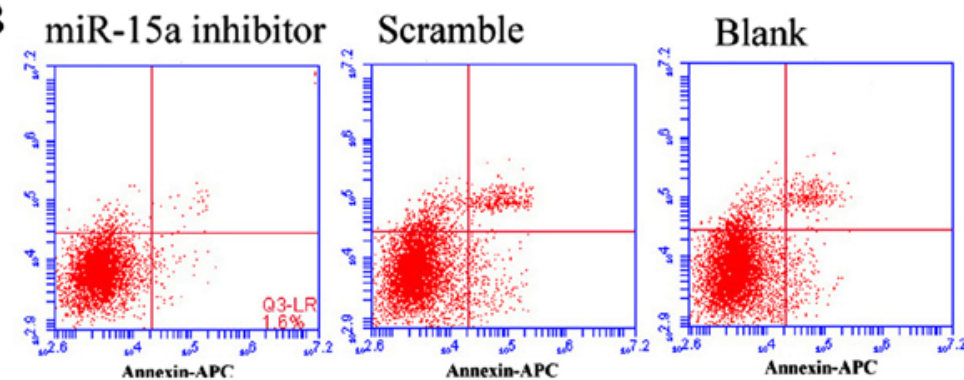

$\mathrm{HPV}^{-}$
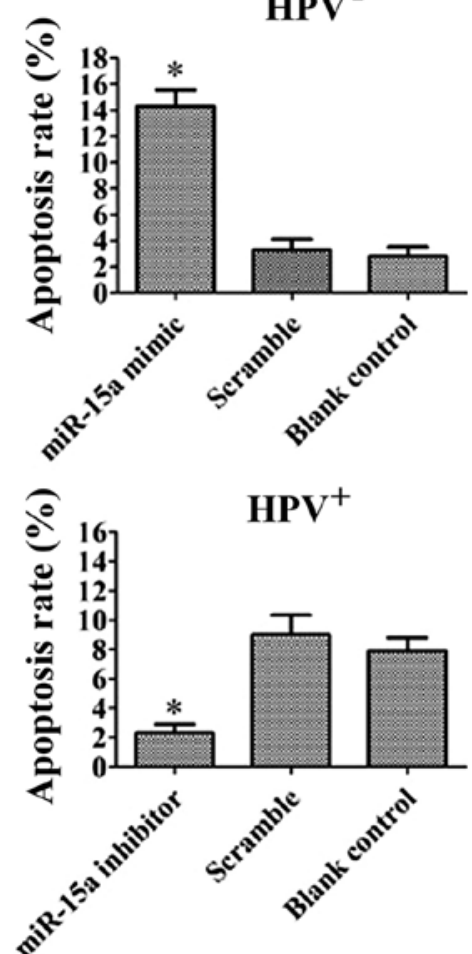

Figure 6. miR-15a induces apoptosis. Cells were transfected with miR-15a mimics or an inhibitor and analyzed by apoptosis assay. (A) Statistically significant $(\mathrm{p}<0.05)$ increases in Annexin V apoptotic cells were observed in the miR-15a mimic-treated FaDu cell lines. (B) The opposite result was observed in the miR-15a inhibitor-treated HPV-positive HSCC. Data are presented as the mean of triplicate experiments.

A

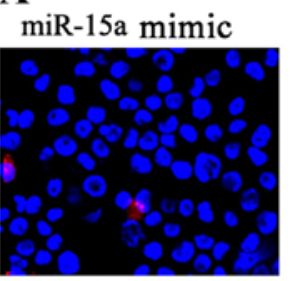

Scramble

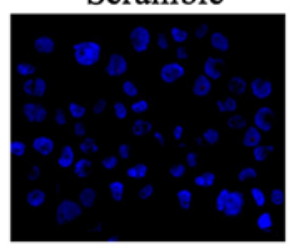

Blank control
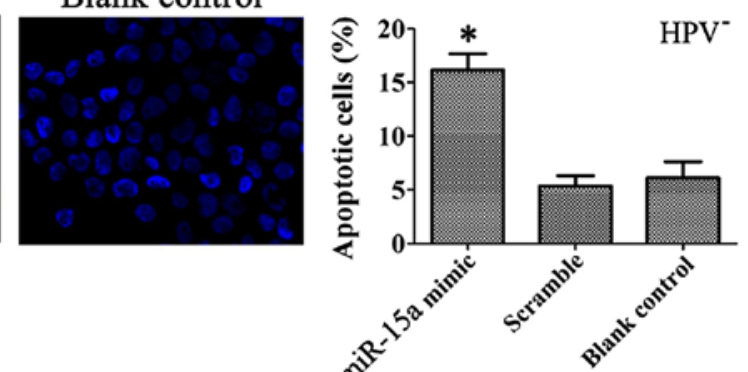

B
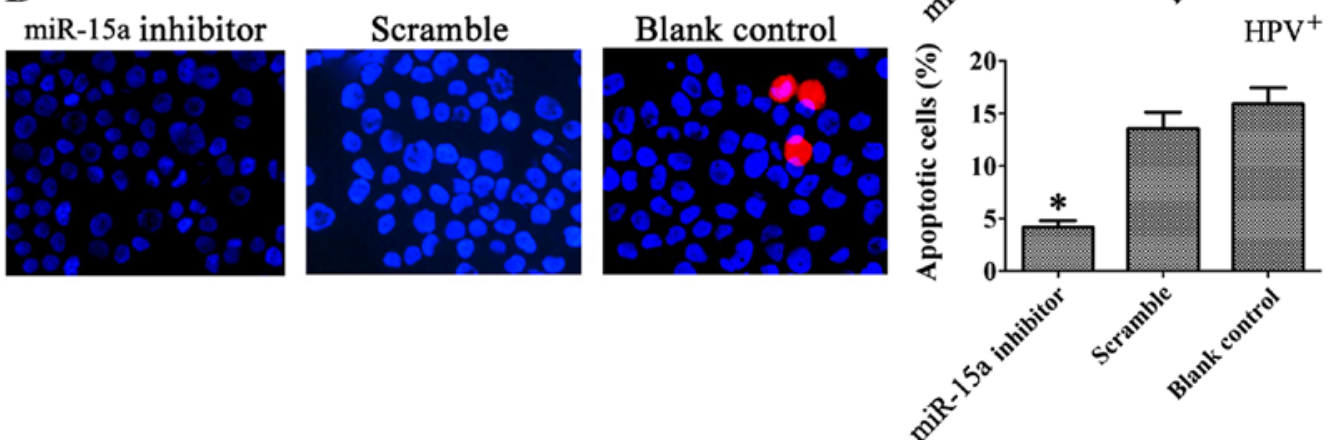

Figure 7. Cell death at $48 \mathrm{~h}$ after the transfection with miR-15a mimics/inhibitor $(20 \mathrm{nM})$. Fragmented nuclei stained with Hoechst 33342/PI indicate apoptotic cell death (magnification, $\mathrm{x} 400$ ). The number of apoptotic cells in the (A) miR-15a mimic-transfected FaDu cells was significantly increased compared with that in the (B) miR-15a inhibitor HPV-positive HSCC. Significant difference between experimental group (miR-15a mimic/inhibitor) and control group (scramble and blank control) $(\mathrm{p}<0.05)$.

to the scramble control $(9.03 \pm 1.35 \%)$ and blank control cells $(7.90 \pm 0.89 \%)$ (Fig. 6). Typical apoptotic changes, such as nuclear fragmentation, were observed in the cells transfected with the miR-15a mimics, and the percentage of apoptotic cells was significantly greater than that of cells transfected with the miR-15a inhibitor, as shown by Hoechst 33342/PI staining 

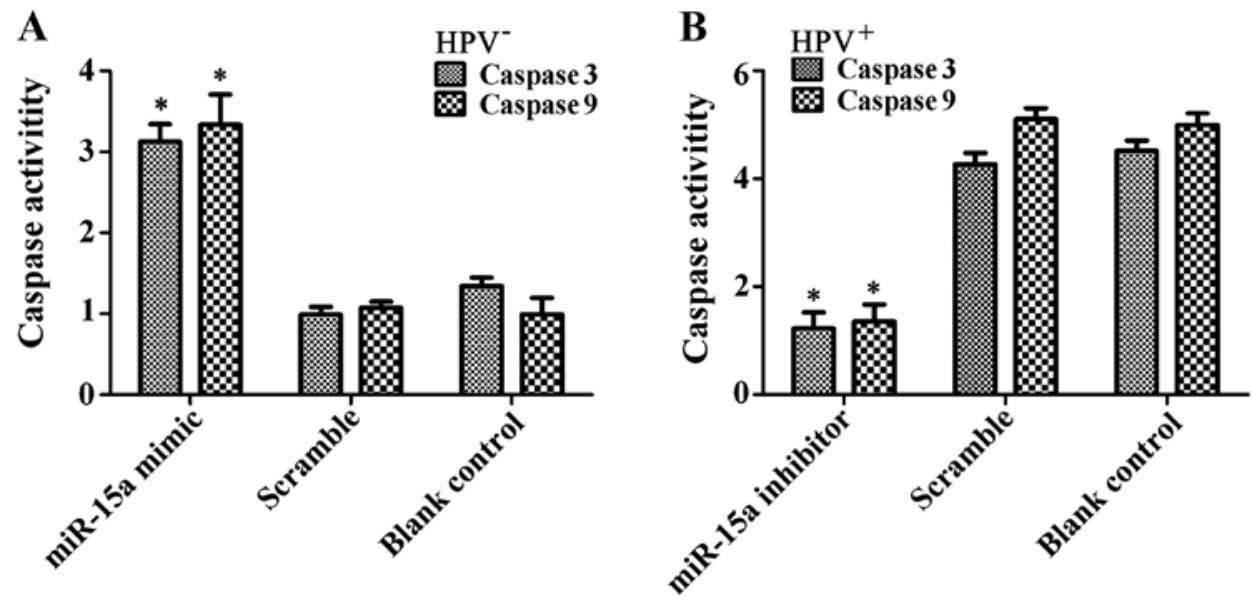

Figure 8. Effect of miR-15a on cell apoptosis. Relative caspase enzyme activity in (A) miR-15a-mimic-treated FaDu cells (HPV-negative) and (B) miR-15a inhibitor-treated HPV-positive HSCC was significantly different $\left({ }^{*} \mathrm{p}<0.01\right)$.

at $48 \mathrm{~h}$ after transfection (Fig. 7). Analysis of caspase-3/-9 activity showed significantly increased enzyme activity in the FaDu cells after miR-15a mimic transfection (p<0.01) (Fig. 8). The results showed that miR-15a promoted $\mathrm{FaDu}$ cell apoptosis in vitro.

\section{Discussion}

HPV-associated hypopharyngeal squamous cell carcinoma (HSCC) is a distinct clinical entity with better prognosis than that of the classical tobacco and alcohol-associated cancer (25). HPV-positive HNSCC harbors wild-type p53, while the classical smoking- and alcohol-induced cancers have mutated p53 (26). In addition, several cellular miRNAs are differentially expressed in HPV-positive HNSCC cell lines and in HPV-negative HNSCC cell lines (27). In our previous study (24), we detected the expression of miR-15a in HNSCC tissues, and found that miR-15a expression was significantly higher in HPV-positive than in HPV-negative HNSCC. These results suggested that miR-15a plays an important role in HPV-positive HNSCC and acts as an anti-oncogene.

In the present study, we examined the expression levels of miR-15a in HPV-positive HNSCC and HPV-negative HNSCC. miR-15a was overexpressed in FaDu cells by transfection with miR-15a mimics. This led to a significant induction of apoptosis as determined by Annexin V-APC/7-AAD staining, Hoechst 33342/PI staining, and caspase-3/-9 expression. Transfection of a miR-15a inhibitor into HPV-positive HSCC had the opposite effects. Taken together, these data indicate that miR-15a may be a novel tumor suppressor in HPV-positive HNSCC.

BCL2L2, also known as BCL-W, is a prosurvival member of the BCL2 protein family and functions as an oncogene. Upregulation of BCL2L2 was reported in various human malignancies, such as gastric, colon and cervical cancers (28). In the present study, BCL2L2 and BCL2 were negatively regulated directly by miR-15a in HPV-positive HSCC as shown by western blotting. miR-15a had a significant effect on BCL2L2 and BCL2 mRNA levels as detected by qRT-PCR, suggesting that miR-15a negatively regulates BCL2L2 and BCL2 expression at the post-transcriptional level. These results indicate that miR-15a may induce apoptosis by targeting BCL2L2 and BCL2 in HPV-positive HSCC.

In conclusion, we found that miR-15a was significantly upregulated in HPV-positive HSCC. miR-15a overexpression induced apoptosis by targeting BCL2L2 and BCL2. Further study is needed to dissect the molecular mechanisms by which miR-15a, BCL2L2 and BCL2 play a role in HPV-positive HSCC to design optimal prevention and treatment strategies.

\section{Acknowledgements}

We are grateful to Professor G.Z. for the helpful comments and suggestions during all stages of the project. The present study was partially supported by a grant from the National Natural Science Foundation of China (no. 81503677).

\section{References}

1. Mendenhall WM and Logan HL: Human papillomavirus and head and neck cancer. Am J Clin Oncol 32: 535-539, 2009.

2. Dayyani F, Etzel CJ, Liu M, Ho CH, Lippman SM and Tsao AS: Meta-analysis of the impact of human papillomavirus (HPV) on cancer risk and overall survival in head and neck squamous cell carcinomas (HNSCC). Head Neck Oncol 2: 15, 2010.

3. Fakhry C, Westra WH, Li S, Cmelak A, Ridge JA, Pinto H, Forastiere A and Gillison ml: Improved survival of patients with human papillomavirus-positive head and neck squamous cell carcinoma in a prospective clinical trial. J Natl Cancer Inst 100: 261-269, 2008.

4. Sinha P, Logan HL and Mendenhall WM: Human papillomavirus, smoking, and head and neck cancer. Am J Otolaryngol 33: 130-136, 2012.

5. Nagadia R, Pandit P, Coman WB, Cooper-White J and Punyadeera $C$ : miRNAs in head and neck cancer revisited. Cell Oncol 36: 1-7, 2013.

6. Michaud DS, Langevin SM, Eliot M, Nelson HH, Pawlita M, McClean MD and Kelsey KT: High-risk HPV types and head and neck cancer. Int J Cancer 135: 1653-1661, 2014.

7. Mendelsohn AH,Lai CK, Shintaku IP, Elashoff DA, Dubinett SM, Abemayor E and St John MA: Histopathologic findings of HPV and p16 positive HNSCC. Laryngoscope 120: 1788-1794, 2010.

8. Benson E, Li R, Eisele D and Fakhry C: The clinical impact of HPV tumor status upon head and neck squamous cell carcinomas. Oral Oncol 50: 565-574, 2014.

9. Dok R and Nuyts S: HPV positive head and neck cancers: Molecular pathogenesis and evolving treatment strategies. Cancers 8: E41, 2016.

10. Grandis J: HER2 and HER3 in $\mathrm{HPV}^{+}$and $\mathrm{HPV}^{-} \mathrm{HNSCC}$ - Response. Clin Cancer Res 22: 1826, 2016. 
11. Antonsson A, Neale RE, Boros S, Lampe G, Coman WB Pryor DI, Porceddu SV and Whiteman DC: Human papillomavirus status and $\mathrm{p} 16^{\mathrm{INK} 4 \mathrm{~A}}$ expression in patients with mucosal squamous cell carcinoma of the head and neck in Queensland, Australia. Cancer Epidemiol 39: 174-181, 2015.

12. Tang J, Wang Z, Chen L, Huang G and Hu X: Gossypol acetate induced apoptosis of pituitary tumor cells by targeting the BCL-2 via the upregulated microRNA $m i R-15 a$. Int J Clin Exp Med 8 : 9079-9085, 2015.

13. Lin K, Farahani M, Yang Y, Johnson GG, Oates M, Atherton M, Douglas A, Kalakonda N and Pettitt AR: Loss of MIR15A and MIR16-1 at 13q14 is associated with increased TP53 mRNA, de-repression of $B C L 2$ and adverse outcome in chronic lymphocytic leukaemia. Br J Haematol 167: 346-355, 2014.

14. Ricieri Brito JA, Gomes CC, Santos Pimenta FJ, Barbosa AA Prado MA, Prado VF, Gomez MV and Gomez RS: Reduced expression of mir15a in the blood of patients with oral squamous cell carcinoma is associated with tumor staging. Exp Ther Med 1: 217-221, 2010

15. Begum S, Cao D, Gillison M, Zahurak M and Westra WH: Tissue distribution of human papillomavirus 16 DNA integration in patients with tonsillar carcinoma. Clin Cancer Res 11: 5694-5699, 2005.

16. Sivars L, Näsman A, Tertipis N, Vlastos A, Ramqvist T, Dalianis T, Munck-Wikland E and Nordemar S: Human papillomavirus and p53 expression in cancer of unknown primary in the head and neck region in relation to clinical outcome. Cancer Med 3: 376-384, 2014

17. Jakscha J, Zlobec I, Storck C, Obermann EC, Tornillo L, Terracciano LM and Fischer CA: The clinical impact of p16 status in fine-needle aspirates of cervical lymph node metastasis of head and neck squamous cell carcinomas. Eur Arch Otorhinolaryngol 270: 661-667, 2013.

18. Keller LM, Galloway TJ, Holdbrook T, Ruth K, Yang D, Dubyk C, Flieder D, Lango MN, Mehra R, Burtness B, et al: p16 status, pathologic and clinical characteristics, biomolecular signature, and long-term outcomes in head and neck squamous cell carcinomas of unknown primary. Head Neck 36: 1677-1684, 2014

19. Tribius S, Hoffmann AS, Bastrop S, Görögh T, Haag J, Röcken C, Clauditz T, Grob T, Wilczak W, Tennstedt P, et al: HPV status in patients with head and neck of carcinoma of unknown primary site: HPV, tobacco smoking, and outcome. Oral Oncol 48: $1178-1184,2012$
20. Fotopoulos $\mathrm{G}$ and Pavlidis N: The role of human papilloma virus and p16 in occult primary of the head and neck: A comprehensive review of the literature. Oral Oncol 51: 119-123, 2015.

21. Schmittgen TD and Livak KJ: Analyzing real-time PCR data by the comparative C(T) method. Nat Protoc 3: 1101-1108, 2008.

22. Rautava J and Syrjänen S: Biology of human papillomavirus infections in head and neck carcinogenesis. Head Neck Pathol 6 (Suppl 1): S3-S15, 2012.

23. Jensen DH, Hedback N, Specht L, Høgdall E, Andersen E, Therkildsen MH, Friis-Hansen L, Norrild B and von Buchwald C: Human papillomavirus in head and neck squamous cell carcinoma of unknown primary is a common event and a strong predictor of survival. PLoS One 9: e110456, 2014.

24. Lu W, Feng L, Li P, Wang Y, Du Y, Chen X, Wu S, Zhao G and Lou W: Effects of HPV-16 infection on hypopharyngeal squamous cell carcinoma and FaDu cells. Oncol Rep 35: 99-106, 2016.

25. Westra WH: Detection of human papillomavirus (HPV) in clinical samples: Evolving methods and strategies for the accurate determination of HPV status of head and neck carcinomas. Oral Oncol 50: 771-779, 2014.

26. Lee HW, Lee SS, Lee SJ and Um HD: Bcl-w is expressed in a majority of infiltrative gastric adenocarcinomas and suppresses the cancer cell death by blocking stress-activated protein kinase/c-Jun NH2-terminal kinase activation. Cancer Res 63: 1093-1100, 2003.

27. Qu J, Zhao L, Zhang P, Wang J, Xu N, Mi W, Jiang X, Zhang C and Qu J: MicroRNA-195 chemosensitizes colon cancer cells to the chemotherapeutic drug doxorubicin by targeting the first binding site of BCL2L2 mRNA. J Cell Physiol 230: 535-545, 2015.

28. Wang F, Liu M, Li X and Tang H: MiR-214 reduces cell survival and enhances cisplatin-induced cytotoxicity via down-regulation of Bcl2l2 in cervical cancer cells. FEBS Lett 587: 488-495, 2013. 